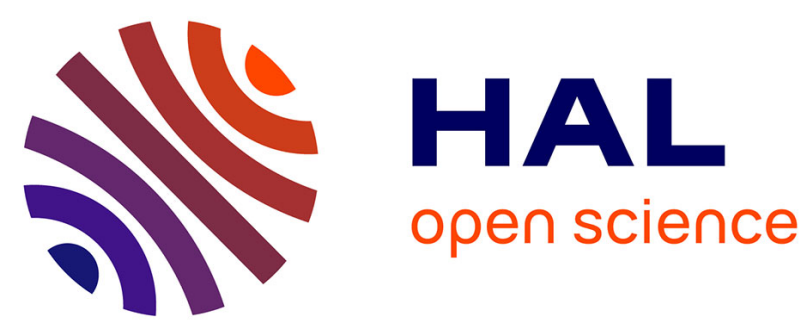

\title{
Preserving the spin transition properties of iron-triazole coordination polymers within silica-based nanocomposites
}

\author{
H. Voisin, C. Aimé, A. Vallée, A. Bleuzen, M. Schmutz, G. Mosser, T. \\ Coradin, Clément Roux
}

\section{To cite this version:}

H. Voisin, C. Aimé, A. Vallée, A. Bleuzen, M. Schmutz, et al.. Preserving the spin transition properties of iron-triazole coordination polymers within silica-based nanocomposites. Journal of Materials Chemistry C, 2017, 5 (44), pp.11542-11550. 10.1039/C7TC04194B . hal-01668720

\section{HAL Id: hal-01668720 \\ https://hal.sorbonne-universite.fr/hal-01668720}

Submitted on 20 Dec 2017

HAL is a multi-disciplinary open access archive for the deposit and dissemination of scientific research documents, whether they are published or not. The documents may come from teaching and research institutions in France or abroad, or from public or private research centers.
L'archive ouverte pluridisciplinaire HAL, est destinée au dépôt et à la diffusion de documents scientifiques de niveau recherche, publiés ou non, émanant des établissements d'enseignement et de recherche français ou étrangers, des laboratoires publics ou privés. 


\title{
Preserving the spin transition properties of iron-triazole coordination polymers within silica-based nanocomposites $\dagger$
}

\author{
H. Voisin, $\ddagger^{a}$ C. Aimé, (DD ${ }^{a}$ A. Vallée, $\S^{a}$ A. Bleuzen, (D) ${ }^{b}$ M. Schmutz, ${ }^{c}$ G. Mosser, (D) ${ }^{a}$ \\ T. Coradin (D) *a and C. Roux*a
}

\begin{abstract}
One dimensional iron(॥) coordination polymers formed from 1,2,4-triazole bridging ligands are a unique class of spin-crossover materials (SCO). The integration of those coordination polymers into devices for practical applications remains a major challenge. Using a nanocomposite approach based on the control of coordination polymer interactions with chemically engineered silica particles, we show that we can achieve in situ gelation, while preserving the SCO properties of the solid state. Tuning the interface between the two phases of a composite provides a unique way to synergistically adjust the material's structure and the cooperativity associated with its transition properties. The strategy described here should allow for bridging the gap between soft and crystalline functional inorganic materials.
\end{abstract}

\section{Introduction}

Spin crossover (SCO) systems are fascinating materials that can be switched from one stable electronic state to another by external stimuli making them very promising for molecular electronics. ${ }^{1,2}$ In particular, 1,2,4-triazoles are known as bridging ligands that form one-dimensional iron(II) coordination polymers. $^{3-6}$ These compounds exhibit cooperative spin transitions between low-spin (LS) and high-spin (HS) states around room temperature, with large thermal hysteresis and a wellpronounced thermochromic effect. ${ }^{7}\left[\mathrm{Fe}(\mathrm{RTrz})_{3}\right][\mathrm{X}] \cdot \mathrm{xH}_{2} \mathrm{O}$ polymers (RTrz $=4$-substituted-1,2,4-triazole, $\mathrm{X}=$ counter anion and $x \mathrm{H}_{2} \mathrm{O}$ stands for non-coordinated water molecules) form a unique class of spin-crossover materials. This is due to their synthetic versatility and the sensitivity of the environment of the iron sites within polymer chains of different lengths and structures that can be diverted to tune the spin-crossover properties. $^{8-12}$ Indeed, the SCO temperature and cooperative

\footnotetext{
${ }^{a}$ Sorbonne Universités, UPMC Univ Paris 06, Collège de France, UMR CNRS 7574, Laboratoire de Chimie de la Matière Condensée de Paris, Paris cedex 05, France. E-mail: cecile.roux@upmc.fr

${ }^{b}$ Institut de Chimie Moléculaire et des Matériaux d'Orsay, CNRS, Université Paris-Sud, Université Paris-Saclay, 91400 Orsay, France

${ }^{c}$ Université de Strasbourg, CNRS, Institut Charles Sadron, 23 rue du Loess-BP 84047, 67034 Strasbourg Cedex 2, France

$\dagger$ Electronic supplementary information (ESI) available. See DOI: 10.1039/c7tc04194b \$ Present address: Department of Materials and Environmental Chemistry, Stockholm University, SE-10691 Stockholm, Sweden.

$\S$ Present address: Institut Lavoisier de Versailles, UMR 8180, Université ParisSaclay, Université de Versailles Saint-Quentin, 45 avenue des Etats-Unis, 78035 Versailles Cedex, France.
}

character can be tuned by the nature of the substituent on the triazole ligand, as well as by playing with the hydration solvent. ${ }^{5}$ In addition, the counter-ion effect has been investigated by different groups. ${ }^{3,9,11,13-15}$ Sulfonate derivatives show capabilities for hydrogen bonding with the lattice water molecules that is responsible for the stabilization of the low spin state. From this solvated state, the removal of water molecules induces the transition to the high-spin state. ${ }^{3}$

One of the main current challenges in spin crossover research is to integrate SCO compounds into devices suitable for practical applications in micro- and nanotechnology. An important issue is to ensure the preservation of the bistability and the cooperative spin transition properties of the compounds at the nanoscale. ${ }^{16-18}$ Different routes have been developed to obtain technologically useful materials including films, multilayers, liquid crystals and nanoparticles. ${ }^{13,19-22}$ Gels have also been proposed as an alternative option to obtain useful materials. $^{23}$ From this perspective, metallogels ${ }^{24,25}$ can be considered as soft matter states of inorganic coordination polymers that are otherwise mostly obtained as powders. This state allows for their application in a wide range of areas, from catalysis to medicine. $^{26-30}$ The successful integration of SCO within a gel must satisfy two requirements: the integration of anions inducing a spin-crossover around room temperature and the presence of gelators. In this context, triazole ligands functionalized with long alkyl chains have been used to obtain gelators. ${ }^{31-34}$ These two features could also be associated within a unique molecular component, using lipophilic sulfonate counter-anions to drive the formation of supramolecular gels. ${ }^{35}$ Alternatively, a series of triazole ligands bearing large lipophilic 
substituents were used to form one-dimensional coordination polymers that could further assemble in a gel phase. ${ }^{10,13}$ These works have evidenced the importance of the dimensional structure (two- or three-) in the cooperativity effect associated with the spin transition, where the temperature dependence of the high spin molar fraction strongly depends on intermolecular interactions. $^{36}$

Alternatively, coordination clusters can be incorporated within matrices to obtain nanocomposites. Such approaches allow tuning the cooperativity between spin-active sites that should be strongly connected to ensure an abrupt spin transition. ${ }^{18,37-39}$ Interestingly, Raza et al. showed that a thin shell of $\mathrm{SiO}_{2}$ formed around a SCO nanoparticle allowed the persistence of a hysteretic behavior due to the rigidity of the matrix, while enhanced cooperativity could be achieved by varying the interparticle distances. ${ }^{40}$ Other works reported the engineering of silica thin films with controlled porosity, doped with spin crossover particles. ${ }^{21,41-44}$ However, in the above-described strategies, the spin transition properties are usually modified compared to the solid-state systems. To address this point, we have developed here a nanocomposite approach where a coordination polymer in suspension is associated with surface-modified silica nanoparticles. Silica nanoparticles serve as chemically versatile platforms to adjust the SCO properties, while providing reticulation nodes for gelation. In particular, negatively charged sulfonate groups grafted at the surface of silica particles were selected to act as counterions of $\left[\mathrm{Fe}(\mathrm{ATrz})_{3}\right]^{2+}$ chains (noted hereafter as Fe/ATrz with ATrz = 4-amino-1,2,4-triazole, Fig. 1a) and further fulfilled the requirements for SCO properties and gelation. Self-standing gels were obtained and fully characterized, highlighting the multiscale complexity of the spin crossover a)

Fe/Atrz $\equiv$

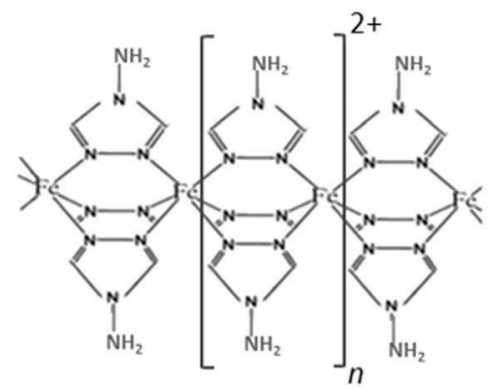

b)

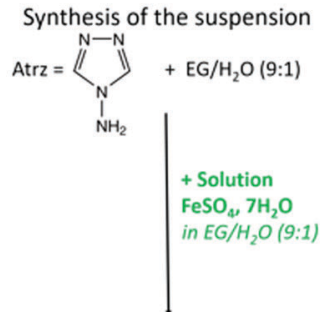

Suspension $\mathrm{Fe} / \mathrm{ATrz} / \mathrm{SO}_{4}$ $\left[\mathrm{Fe}^{2+}\right]=0.1 \mathrm{M} ;$ Atrz/Fe : $6 / 1$

\begin{tabular}{c|c} 
Resuspension \\
in $\mathrm{EG} / \mathrm{H}_{2} \mathrm{O}(9: 1)$
\end{tabular}$\| \begin{aligned} & \text { Washing } \mathrm{EtOH} \\
& \text { And Drying }\end{aligned}$

Dried Suspension $\mathrm{Fe} / \mathrm{ATrz} / \mathrm{SO}_{4}$ c) Synthesis of the composite

$$
\begin{aligned}
& \mathrm{NP}-\mathrm{SiSO}_{3}=\mathrm{O}^{\mathrm{SO}_{3}}+\mathrm{EG} / \mathrm{H}_{2} \mathrm{O}(9: 1) \\
& \mathrm{SO}_{\mathrm{SO}_{3}} \mid \begin{array}{l}
+\mathrm{Atrz}= \\
\text { In } \mathrm{EG} / \mathrm{H}_{2} \mathrm{O}
\end{array} \\
& \text { (9:1) }
\end{aligned}
$$

Composite NP-SiSO 3 @Fe/ATrz/ $/ \mathrm{SO}_{4}$

$\left[\mathrm{Fe}^{2+}\right]=0.1 \mathrm{M} ; \mathrm{Atrz} / \mathrm{Fe}: 6 / 1 ; \mathrm{Fe} / \mathrm{SO}_{3}: 20 / 1$

Resuspension $\|$ Washing EtOH

in $\mathrm{EG} / \mathrm{H}_{2} \mathrm{O}(9: 1)$ And Drying

Dried Composite NP-SiSO ${ }_{3}$ Fe/ATrz/ $/ \mathrm{SO}_{4}$
Fig. 1 Schematic representation of (a) a coordination polymer chain, and of the synthesis route for (b) the Fe/ATrz/SO suspension and (c) the $\mathrm{NP}-\mathrm{SiSO}_{3} \mathrm{aFe} / \mathrm{ATrz} / \mathrm{SO}_{4}$ composite. phenomenon. This work shows that it is possible to establish a clear relationship between structural percolation and cooperativity effects. This sheds light on the fact that such a nanocomposite approach allows for bridging the gap between soft and crystalline inorganic materials.

\section{Results and discussion}

\section{Preparation and properties of a particle-free system (Fe/ATrz/SO $\mathrm{SO}_{4}$ suspension)}

In a first step, the possibility of obtaining a metastable gel with an abrupt and reversible spin transition was explored with $\mathrm{Fe}^{2+}$ and simple RTrz derivatives (HTrz or ATrz). If we exclude the nanoparticle syntheses by the reverse-micelle method, a single paper describes the formation of metallogels based on $\left[\mathrm{Fe}(\mathrm{ATrz})_{3}\right](2 \mathrm{~ns})_{2}(2 \mathrm{~ns}=2$-naphalenesulfonate $)$ in $\mathrm{N}, \mathrm{N}$-dimethylformamide solvent at a high iron concentration of $\left[\mathrm{Fe}^{2+}\right]=$ $0.1 \mathrm{M} .{ }^{45}$ We hypothesized that a careful selection of iron(II) salts should allow for the gelation of other polar solvents from HTrz or ATrz. Since it is difficult to pinpoint a general strategy to obtain a metallogel in polar solvents, a preliminary screening was performed for different polar solvents (glycerol, ethylene glycol, water and ethanol) with various $\mathrm{Fe}^{2+}$ salts (such as $\mathrm{FeBr}_{2}$, $\mathrm{Fe}\left(\mathrm{BF}_{4}\right)_{2}$ and $\left.\mathrm{Fe}\left(\mathrm{SO}_{4}\right) \cdot 7 \mathrm{H}_{2} \mathrm{O}\right)$ at high iron concentration $\left(\left[\mathrm{Fe}^{2+}\right]=\right.$ $0.1 \mathrm{M}$ ) and a molar $\mathrm{RTr} / \mathrm{Fe}^{2+}$ ratio of $3 / 1$. This ratio is the stoichiometric ratio of the ideal coordination polymer $\left[\mathrm{Fe}(\mathrm{RTrz})_{3}\right]^{2+}$. These preliminary tests led to three different systems: (i) amorphous gels with poorly reversible spin transition properties in polyol solvents (for example $\left[\mathrm{Fe}(\mathrm{HTrz})_{3}\right] \mathrm{Br}_{2}$ in glycerol). These gels are formed from pink solutions indicative of the presence of low spin species before gelation (Fig. S1a, ESI $\dagger$ ). (ii) Pink crystalline precipitates were obtained in ethanol or water (for example $\left[\mathrm{Fe}(\mathrm{ATrz})_{3}\right] \mathrm{SO}_{4}$ in water) (Fig. S1b, ESI $\dagger$ ) exhibiting the same reversible SCO properties as in the solid state. (iii) A stable white suspension (denoted as $\mathrm{Fe} / \mathrm{ATrz} / \mathrm{SO}_{4}$ ) was achieved only using $\mathrm{FeSO}_{4}$ in combination with ATrz in a mixture of ethylene glycol (EG) and water in a 9:1 volume ratio (Fig. 1b). Noticeably, the molar ATrz/ $\mathrm{Fe}^{2+}$ ratio used for this synthesis was increased to $6: 1$ in order to promote the expected compound, $\left[\mathrm{Fe}(\mathrm{ATrz})_{3}\right] \mathrm{SO}_{4},{ }^{45,46}$ due to the strong complexing ability of $\mathrm{SO}_{4}{ }^{2-}$ anions for $\mathrm{Fe}$ (II) ions. Upon ageing, the initial $\mathrm{Fe} / \mathrm{ATrz} / \mathrm{SO}_{4}$ viscous suspension changed from white to pink. In addition, we observed a color change (pink to white) upon heating that was reversible upon cooling. Before investigating the possibility of making a gel out of this system via a composite strategy, we characterized the properties associated with this observed color change in detail.

After 9 days of ageing, the thermochromic behavior of the suspension could be followed by visible light absorption measurements (Fig. 2). As for all other thermal experiments, we discuss data obtained during the second thermal cycle to get rid of the synthesis thermal history of the sample. At room temperature $(293 \mathrm{~K})$, the UV-Vis absorbance spectrum of the pink sample showed a band at $\lambda c a .520 \mathrm{~nm}$ with a diffusion background. The latter is due to light scattering effects and hampers the exact determination of the band characteristics. 


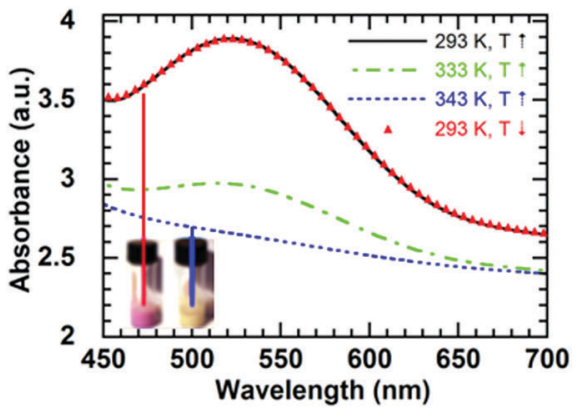

Fig. 2 Evolution of the UV-Visible spectrum of the Fe/ATrz/SO ${ }_{4}$ suspension aged for 9 days along a second temperature cycle in the heating (line) and cooling (symbols) modes (293-343 K in steps of $10 \mathrm{~K}$, scan rate about $5 \mathrm{~K} \mathrm{~min}^{-1}$ ). The inset shows the visual aspect of the samples.

By subtracting the diffusion background, the maximum band and the molar extinction coefficient could be estimated to be $\lambda=532 \mathrm{~nm}$ and $\varepsilon=80 \mathrm{~cm}^{-1} \mathrm{~mol}^{-1} \mathrm{~L}$, respectively corresponding to the $\mathrm{d}-\mathrm{d}$ electronic transition of the iron ions in the low spin state $\left({ }^{1} \mathrm{~A}_{1 \mathrm{~g}} \rightarrow{ }^{1} \mathrm{~T}_{2 \mathrm{~g}}\right) .{ }^{47}$ It is worth mentioning that the molar extinction coefficient refers to a repeat unit of the polymer (i.e. not to a polymer molecule). This band started to fade at $330 \mathrm{~K}$ along with the discoloration of the sample and reached a minimum at $340 \mathrm{~K}$, when the sample was completely white indicative of the high spin state. Cooling the sample back to room temperature led to the immediate reappearance of the peak at $520 \mathrm{~nm}$ with the sample turning pink again. This indicates a reversible spin change.

Differential scanning calorimetry (DSC) was used to further investigate the SCO phenomenon and to follow its evolution during the ageing of the suspension (Fig. 3a). At a rate of $5 \mathrm{~K} \mathrm{~min}{ }^{-1}$, no thermal event could be evidenced for the suspension aged for one day after mixing that remained white. However, a small broad endothermic transition was found after three days around $T_{\max }^{\uparrow}=316 \mathrm{~K}$, accompanied upon cooling by a small broad exothermic peak around $T_{\max }^{\downarrow}=302 \mathrm{~K}$. Over the next six days, the peaks grew in intensity and became narrower. An endothermic peak at $T_{\max }^{\uparrow}=325 \mathrm{~K}$ and an exothermic peak at $T_{\max }^{\downarrow}=310 \mathrm{~K}$ were observed respectively in warming and cooling modes. This is indicative of a first-order phase transition. The peak separation suggests a hysteresis loop width of $15 \mathrm{~K}$. After 20 days, the DSC peaks were shifted towards higher temperatures $\left(T_{\max }^{\uparrow}=327 \mathrm{~K}, T_{\max }^{\downarrow}=312 \mathrm{~K}\right.$ ) but the hysteresis loop width was not significantly modified. This is consistent with a cooperative spin crossover behavior. Interestingly, the hysteresis loop occurred at lower temperature than those previously reported in the literature; typically $T_{\max }^{\uparrow}=346 \mathrm{~K}$, $T_{\max }^{\downarrow}=319 \mathrm{~K}$ for a hysteresis of $27 \mathrm{~K}$ for the hydrated complex. ${ }^{48}$ This difference in $T_{\max }$ may be attributed to a solvent effect (water vs. $\mathrm{H}_{2} \mathrm{O} / \mathrm{EG}$ ).

Parallelly, the structural evolution of the suspension upon ageing was monitored by X-ray powder diffraction (XRPD) (Fig. 3b). One day after synthesis, the diffractogram showed two broad peaks centered at $2 \theta=25^{\circ}$ and $42^{\circ}$, indicative of an amorphous phase. Later on, several well-defined diffraction
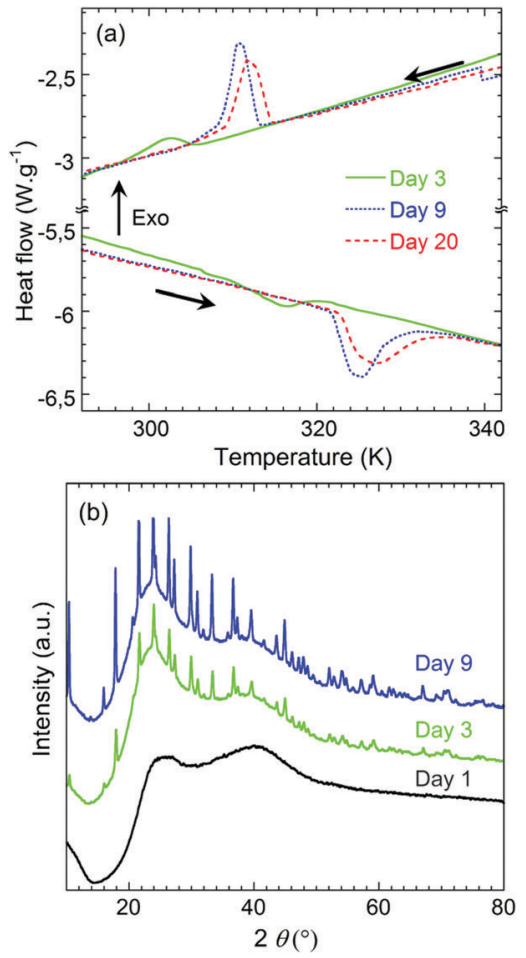

Fig. 3 Evolution of (a) the DSC curve over a second heating/cooling cycle at $5 \mathrm{~K} \mathrm{~min}^{-1}$ and (b) XRPD diffractograms of the $\mathrm{Fe} / \mathrm{ATrz} / \mathrm{SO}_{4}$ suspension upon ageing.

peaks emerged and their intensities relative to the background increased with time until a maximum was reached after nine days. Yet the broad peaks were still clearly visible and the low-angle component increased in intensity with ageing. This suggests either the co-existence of two distinct phases of different crystallinity or a single phase exhibiting a semicrystalline behavior. Variable temperature XRPD analyses were performed on the suspension aged for 9 days. Most of the diffraction peaks obtained at 298 and $353 \mathrm{~K}$ overlapped in the $2 \theta$ range of $7-60^{\circ}$ (Fig. S2, ESI $\dagger$ ) except in the $20-35^{\circ}$ range (Fig. 4a). The diffraction peaks underwent a shift towards smaller $2 \theta$ values upon heating that was fully reversible upon cooling. A more detailed variable temperature analysis was performed by recording XRPD patterns between $298 \mathrm{~K}$ and $348 \mathrm{~K}$ in steps of $5 \mathrm{~K}$ (mean scan rate of $1 \mathrm{~K} \mathrm{~min}^{-1}$ ) focusing on the diffraction peaks at $25.3^{\circ}$ (present at $353 \mathrm{~K}$ ) and $26.2^{\circ}$ (present at $298 \mathrm{~K}$ ) for which this shift was particularly significant. As shown in Fig. $4 \mathrm{~b}$, the intensity of the peak at $26.2^{\circ}$ decreased with increasing temperature until the peak disappeared at $328 \mathrm{~K}$. Upon cooling, it reappeared at $318 \mathrm{~K}$ and reached its maximal intensity at $308 \mathrm{~K}$. In contrast, the peak at $25.3^{\circ}$ was evident from $318 \mathrm{~K}$ and raised in intensity up to $348 \mathrm{~K}$. Its intensity started to decrease upon cooling back to $318 \mathrm{~K}$ and disappeared at $308 \mathrm{~K}$. This indicates the coexistence of two crystalline phases associated with a reversible first order spin-transition (LS/HS), in fair agreement with the DSC data.

Further information was obtained using electron microscopy (Fig. 5). After 9 days of ageing, SEM images revealed 

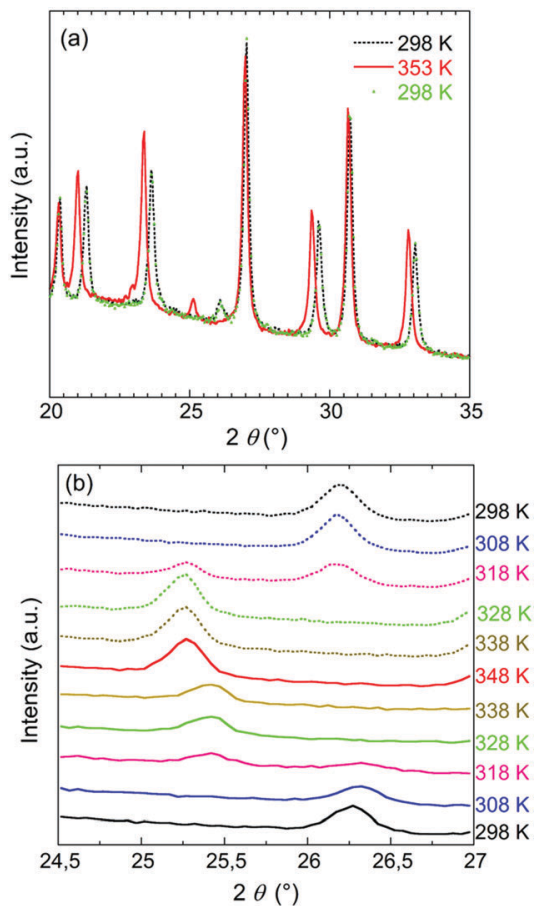

Fig. 4 Evolution of the XRPD diffractogram of the Fe/ATrz/SO $\mathrm{S}_{4}$ suspension aged for 9 days (a) in a large range of $2 \theta$ at $298 \mathrm{~K}$ before and after heating, and at $353 \mathrm{~K}$, (b) in the restricted $2 \theta$ range of $24.5-27^{\circ}$ upon a second cycle of heating (lines) and cooling (dashed lines) (between 298 and $348 \mathrm{~K}$ in steps of $10 \mathrm{~K}$; mean scan rate $=1 \mathrm{~K} \mathrm{~min}^{-1}$ ).

the general aspects of the crystalline phase, consisting predominantly of needle-shaped particles typically $1 \mu \mathrm{m}$ long and $100 \mathrm{~nm}$ wide forming a porous network. Cryo-TEM imaging allowed for the clear observation of an amorphous phase appearing as a grayish matrix embedding the needle-like particles. These observations, together with the well-established correlation between the extent of the spin transition and the crystallinity of the sample, suggest that the ageing process corresponds to a crystallization phenomenon. Given the size of the needles $(1 \mu \mathrm{m}$ long) and the expected Fe...Fe distance (ca 3.5 to $3.8 \AA$ ), the crystals are made of $c a .3000 \mathrm{Fe}$ atoms. This very high value may result from the association of smaller crystals. Indeed, the existence of a reversible and hysteretic SCO process relies on strong interactions between coordination polymer chains that can be achieved within such crystals. In contrast, such interactions may be more limited in the amorphous phase. In this context, it is
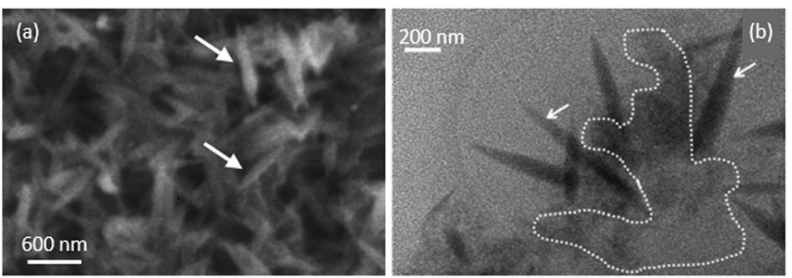

Fig. 5 (a) SEM and (b) cryo-TEM images of a 9 day-old Fe/ATrz/SO 4 suspension. The amorphous matrix is highlighted in the dotted area, and the crystalline needles by the arrows. worth pointing out that the investigation of the samples using Small Angle X-ray Scattering (SAXS) showed no characteristic signature, suggesting the absence of periodic organization at the nanometer scale and above.

\section{Preparation and properties of NP-SiSO ${ }_{3} @ \mathrm{Fe} / \mathrm{ATrz} / \mathrm{SO}_{4}$ composite gels}

Achieving a composite gel structure by addition of particles is a major challenge in self-assembling systems, as sufficient interactions should exist between the two components to achieve percolation while avoiding colloidal destabilization and/or phase separation. This was all the more delicate for the system described here as SCO properties are known to be very sensitive to chemical conditions. In this context, it has been previously shown that stable Nafion-[Fe(HTrz $\left.)_{3}\right]^{2+}$ composites exhibiting spin conversion properties could be obtained thanks to the functionalization of the matrix with sulfonate moieties that interact with the inorganic polymer. ${ }^{37}$ We have thus focused our work on sulfonate-functionalized silica particles ( $\left.\mathrm{NP}^{-\mathrm{SiSO}_{3}}\right)$ that could act as counter-ions of the Fe/ATrz chains. The synthesis summarized in Fig. 1c consists in adding $\mathrm{NP}^{-\mathrm{SiSO}_{3}}$ $\left(200 \mathrm{~nm}\right.$ in diameter) to $\mathrm{EG} / \mathrm{H}_{2} \mathrm{O}(9 / 1)$ solution of $\mathrm{FeSO}_{4} \cdot 7 \mathrm{H}_{2} \mathrm{O}$, before ligand addition, to induce the formation of a homogeneous gel. This choice proved to be adequate, as gelation occurred after 20 hours when enough particles $\left(140 \mathrm{mg} \mathrm{mL}^{-1}\right.$ $\mathrm{NP}_{-} \mathrm{SiSO}_{3}$, corresponding to a $\mathrm{Fe}: \mathrm{SO}_{3}$ molar ratio of $20: 1$ ) were added to the system (Fig. S3, ESI $\dagger$ ). The observed gel, denoted as $\mathrm{NP}-\mathrm{SiSO}_{3} @ \mathrm{Fe} / \mathrm{ATrz} / \mathrm{SO}_{4}$, initially white turned pink after 1 day. In contrast, the use of thiol-bearing nanoparticles led to a precipitation of the $\left[\mathrm{Fe}(\mathrm{ATrz})_{3}\right] \mathrm{SO}_{4}$ compound. Interestingly, the addition of bare silica nanoparticles resulted in the formation of a dark precipitate, that probably corresponds to iron oxide particles originating from the oxidation of $\mathrm{Fe}(\mathrm{II})$ after coming into contact with the silanol groups at the surface of the particles. This indicates that although the particle surface is not fully covered with sulfonate groups upon functionalization (given that a $200 \mathrm{~nm}$ diameter $\mathrm{NP}^{-\mathrm{SiSO}_{3}}$ presents $c a .10^{5}$ sulfonate groups at its surface compared to $c a .5 \times 10^{5}$ silanol groups for bare particles, see the ESI $\dagger),{ }^{49,50}$ it is sufficient to protect growing iron chains against oxidation.

Rheological studies have been conducted at room temperature to study the mechanical properties and confirmed the gel nature of the composite obtained with NP-SiSO $3\left(140 \mathrm{mg} \mathrm{mL}^{-1}\right.$, corresponding to $\mathrm{Fe}: \mathrm{SO}_{3}$ molar ratio of $20: 1$ ) and aged for 9 days (Fig. 6a). The average storage modulus $G^{\prime}$ ranged between 5 and $8 \mathrm{kPa}$ as a function of frequency, whereas the loss modulus $G^{\prime \prime}$ was one order of magnitude lower. Noticeably, in the high frequency domain, both $G^{\prime}$ and $G^{\prime \prime}$ tended to decrease, a behavior that was already observed for colloidal suspensions of anisotropic particles. ${ }^{51}$ Doubling the particle content to $300 \mathrm{mg} \mathrm{mL} \mathrm{m}^{-1}$ induced a $c a$. two-fold increase in $G^{\prime}$ and $G^{\prime \prime}$ values, illustrating the key contribution of $\mathrm{NP}^{-\mathrm{SiSO}_{3}}$ to the mechanical properties of the gel. However, at such high silica concentration, the preparation of a homogeneous composite was difficult due to the immediate gelation so that these conditions were not explored further. The rheological properties 

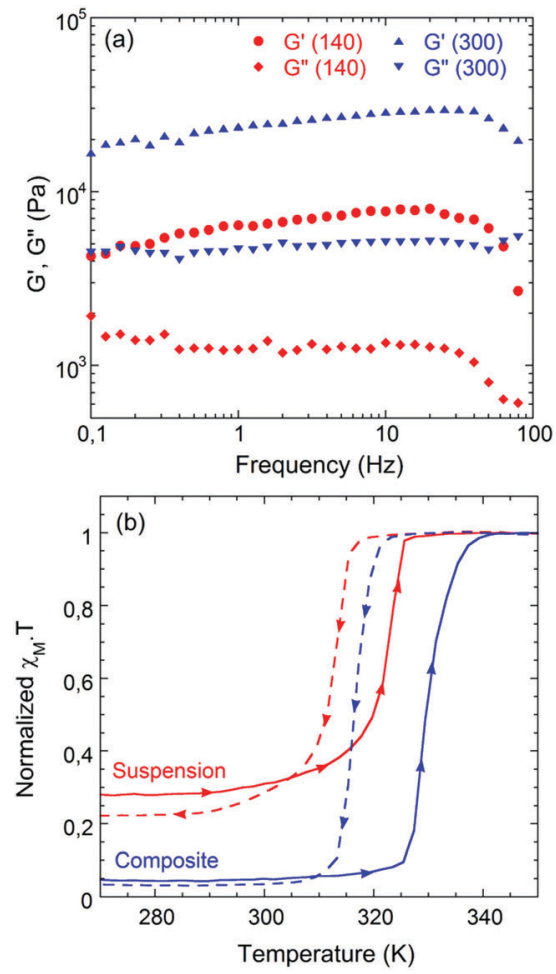

Fig. 6 (a) Rheological profiles under shear stress, at a fixed deformation of $0.1 \%$ of the NP-SiSO ${ }_{3} \mathrm{aFe} / \mathrm{ATrz} / \mathrm{SO}_{4}$ composites with $\mathrm{NP}-\mathrm{SiSO}_{3}$ concentrations of 140 and $300 \mathrm{mg} \mathrm{mL}^{-1}$ (Fe: $\mathrm{SO}_{3}$ molar ratio of $20: 1$ and $10: 1$ respectively). (b) Thermal dependence of normalized $\chi_{M} T$ product of the $\mathrm{Fe} / \mathrm{ATrz} / \mathrm{SO}_{4}$ suspension and $\mathrm{NP}-\mathrm{SiSO}_{3} @ \mathrm{Fe} / \mathrm{ATrz} / \mathrm{SO}_{4}$ composite gel upon a second cycle (scan rate of $5 \mathrm{~K} \mathrm{~min}^{-1}$ ).

of the particle-free suspension could not be measured in this configuration due to its purely liquid behavior.

Compared to the particle-free suspension, XRPD diffractogram of the composite after the same ageing of 9 days showed an enhanced contribution of the broad reflection peak at ca. $25^{\circ}$, in agreement with the diffractogram of amorphous silica (Fig. S4, ESI $\dagger$ ). However, no significant modification of the crystalline phase (i.e. no angular shift or change in the width of the diffraction peaks) of the inorganic polymer network could be evidenced upon particle addition.

Magnetometry measurements have been performed to compare the behavior of the systems with and without particles. Since comparable volumes of the suspension and gel containing the same amount of $\mathrm{Fe}(\mathrm{II})$ ions were analyzed, the product $\chi_{\mathrm{M}} T$ ( $\chi_{\mathrm{M}}$ molar paramagnetic susceptibility) was normalized in order to get the most appropriate comparison. In both cases, a thermal hysteresis was obtained (Fig. 6b). The residual amount of high spin species at low temperature was higher in the absence of $\mathrm{NP}_{-} \mathrm{SiSO}_{3}$ and increased with cycling. In the presence of $\mathrm{NP}^{-\mathrm{SiSO}_{3}}$, a reversible transition was observed. The particles also led to higher upward and downward transition temperatures $\left(T^{\uparrow}=330 \mathrm{~K}\right.$ and $T_{\downarrow}=316 \mathrm{~K}$, respectively) compared to the system without particles $\left(T^{\uparrow}=321 \mathrm{~K}\right.$ and $T_{\downarrow}=312 \mathrm{~K}$, respectively) and a broadening of the hysteresis width $(\Delta T=9 \mathrm{~K}$ and $14 \mathrm{~K}$ for the particle-free suspension and the composite gel, respectively). Parallelly, DSC analysis showed upward and downward transition temperatures of $T_{\max }^{\uparrow}=328 \mathrm{~K}$ and $T_{\max }^{\downarrow}=315 \mathrm{~K}$ respectively, with a hysteresis width of $13 \mathrm{~K}$ (Fig. S5, $\dagger$ ). Taking into account the $\mathrm{Fe}^{2+}$ concentration per $\mathrm{g}$ of sample of $\mathrm{ca} .8 .3 \times$ $10^{-4} \mathrm{~mol} \mathrm{~g}^{-1}$, the transition enthalpy for the inorganic component can be estimated to be around $12 \mathrm{~kJ} \mathrm{~mol}^{-1}$. Note that this value is probably underestimated as there is a possibility that a fraction of the $\mathrm{Fe}(\mathrm{II})$ ions is not involved in the transition phenomenon. Yet, the calculated value is in the intermediate range of transition enthalpy for already reported iron(II)-based spin transition systems. ${ }^{52,53}$ Thus it is consistent with a cooperative SCO behavior with a hysteresis width of $13 \mathrm{~K}$. It must be pointed out that the corresponding entropy value is around $40 \mathrm{~J} \mathrm{~mol}^{-1} \mathrm{~K}^{-1}$, indicating a vibrational contribution to the transition. Altogether, these data suggest an enhancement of (i) the ligand field of the iron centers and (ii) the cooperativity between the spin carriers. This supports the existence of significant interactions between the sulfonate groups of the $\mathrm{NP}_{-} \mathrm{SiSO}_{3}$ and the inorganic polymer.

To further investigate the interface between the inorganic polymer and the $\mathrm{NP}^{-S_{S} \mathrm{SO}_{3}, 9}$ day-aged composite gels were observed by TEM and SEM. This evidenced the uniform dispersion of $\mathrm{NP}^{-\mathrm{SiSO}_{3}}$ in the iron-ATrz network. Similar to the suspension, the inorganic network was composed of needles while the amorphous phase was difficult to distinguish due to the presence of the NP-SiSO 3 particles (Fig. 7a and b). Freezefracture was then used to allow for the preservation of the hydrated environment of the system before imaging by TEM after replication. ${ }^{54}$ Particle imprints were seen as round craters with irregular marks radiating from them that can be associated with the iron-triazole polymer chains, physically interacting with the silica surface (Fig. 7c and d). Those chains were integrated in the global amorphous polymer network, linking the particles to the system. Some needle-shaped iron-ATrz nanoparticles were also clearly visualized by this technique (white arrows on Fig. 7d). These observations clearly evidence the close interface between the components of the composite system.

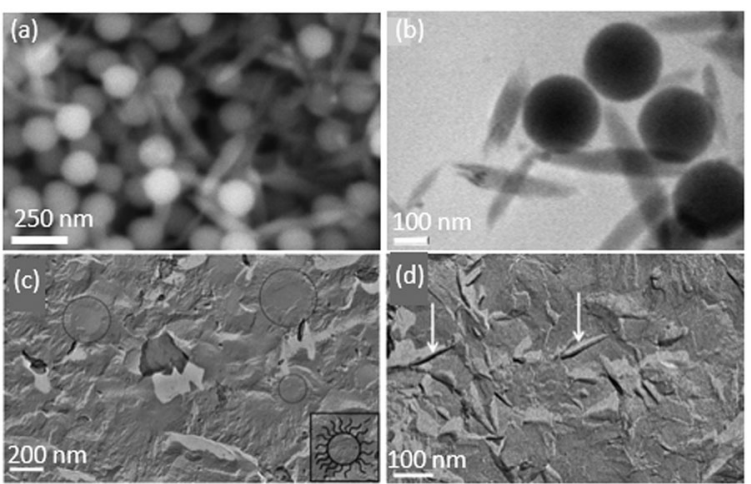

Fig. 7 Composite gel NP-SiSO 3 (aFe/ATrz/SO 4 imaged by (a) SEM-FEG, (b) cryo-TEM, (c and d) freeze-fractured TEM. (c) Several imprints of $\mathrm{NP}-\mathrm{SiSO}_{3}$ can be seen (open circles in the picture) with a typical radiating pattern around their perimeter as outlined in the inset. (d) Arrows indicate needle-like structures corresponding to the $\left[\mathrm{Fe}(\mathrm{Atrz})_{3}\right] \mathrm{SO}_{4}$ particles. 
As pointed out earlier, XRD and DSC studies on the influence of ageing on the particle-free suspension have suggested that the spin transition properties, related to the existence of high intra- and inter-chains interactions, mainly originate from the crystalline phase. Magnetometry measurements and XRPD studies of the composite have indicated that the addition of the $\mathrm{NP}_{-} \mathrm{SiSO}_{3}$ has a significant impact on the spin transition without modifying the crystallinity of the sample. Parallelly, rheology and TEM characterizations have evidenced strong interactions between the particles and the amorphous part of the iron-ATrz matrix. Taken together, these observations support the idea that this amorphous phase itself plays an important role in the spin transition phenomenon. To clarify this point, we prepared solvent-free solid composites. However, as ethylene glycol cannot be evaporated under ambient conditions, it was first exchanged for ethanol in a 9-day matured composite and then air-dried, leading to a pink powder (Fig. 1c). As seen in Fig. 8a, the broad amorphous peaks on the diffractogram decreased in intensity after drying. The remaining peak can be attributed to the presence of silica particles. The well-defined diffraction pattern is identical to that of the initial composite, indicating that the crystalline structure has not been significantly affected by the drying process. The dried powder was then re-exposed to the ethylene glycol/water mixture $(1 \mathrm{~mL}, 9: 1$ volume ratio). The resulting sample recovered its original gel texture and its diffractogram was similar to that of the starting system, indicating the physical reversibility of the system. Similar observations were made for the particle-free system upon drying and re-solvation (Fig. S6, ESI $\dagger$ ).

The magnetic properties and thermal behavior of the dried suspension and composite were also studied (Fig. S7, ESI $\dagger$ for

(a)
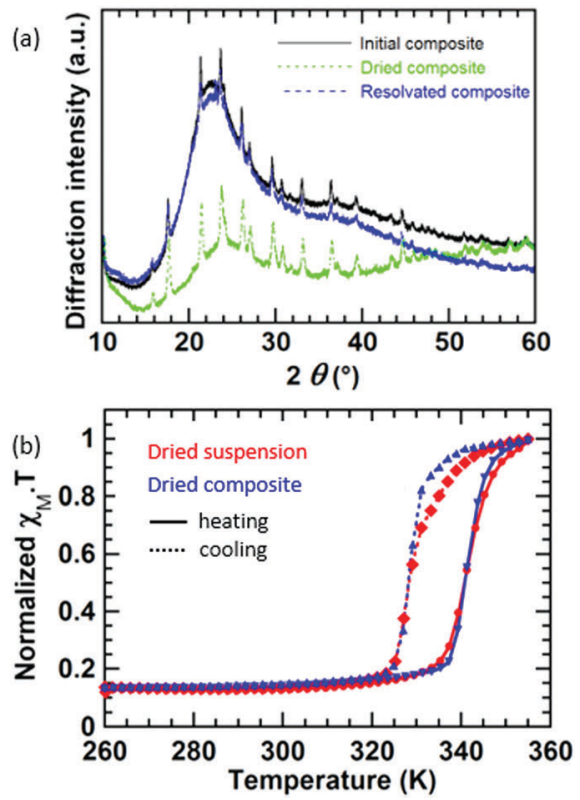

Fig. 8 (a) XRPD diffractograms of the initial, dried and resolvated $\mathrm{NP}-\mathrm{SiSO}_{3} \mathrm{aFe} / \mathrm{ATrz} / \mathrm{SO}_{4}$ composites. (b) Thermal dependence of normalized $\chi_{M} T$ product (performed at a scan rate of $5 \mathrm{~K} \mathrm{~min}^{-1}$ ) of the dried suspension and composite.
DSC data). Fig. 8b shows the magnetic properties of the two dried systems exhibiting similar hysteretic behavior except for a more abrupt HS/LS transition upon cooling in the presence of $\mathrm{NP}-\mathrm{SiSO}_{3}$. In addition, the upward and downward transitions are shifted to higher temperatures compared to their solvated states $\left(T^{\uparrow}=343 \mathrm{~K}\right.$ and $T_{\downarrow}=329 \mathrm{~K}$, see Table S1, ESI $\left.\dagger\right)$, indicative of a modification of the environment of the $\mathrm{Fe}(\mathrm{II})$ centers. Interestingly, the width of the hysteresis is similar for the two powders and close to that of the solvated composite (i.e. $14 \mathrm{~K}$ ). This indicates that in dried systems the presence of particles has a limited impact on the SCO properties.

It is therefore possible to describe these systems in the following manner (Fig. 9). (a) In the suspension, needle-shaped crystals are surrounded by an amorphous solvated network of Fe/ATrz chains. The spin transition properties mainly originate from these crystals. (b) Upon adding $\mathrm{NP}^{-\mathrm{SiSO}_{3}}$, the formation of a gel evidences the percolation of the crystals/matrix assembly. (c) Upon desolvation of the suspension, it can be suggested that the amorphous phase undergoes a shrinking process, increasing the local density in Fe/ATrz chains and embedding the crystals. The high degree of similarity between the diffractograms of the initial and the resolvated systems, in the absence or presence of NP-SiSO ${ }_{3}$, led us to hypothesize that the crystallinity of the inorganic network was identical in all systems. This suggests that the different widths of hysteresis between the suspension, the composite and the dried systems should arise from a subtle change in the interactions between the crystals due to some modifications in their environments. In particular, depending on the rigidity of the host, long-range elastic interactions can be mediated or dampened, leading to an increase or decrease of the cooperativity in the system. This has been shown to result in strong modification of the SCO properties of entrapped microcrystalline objects ${ }^{55}$ and conservation of wide hysteresis in dispersed nanoparticles. ${ }^{56}$ Other parameters, such as distance between objects or the strength of their interactions with the matrix should also play a role in the modification of their behavior. In our system, the percolation of the amorphous phase or its desolvation seems to increase the cooperativity between iron-ATrz crystals to a similar extent, leading to a widening of the hysteresis from $9 \mathrm{~K}$ in the sol state to $14 \mathrm{~K}$. Thus the mediation of the interactions through percolated solvated
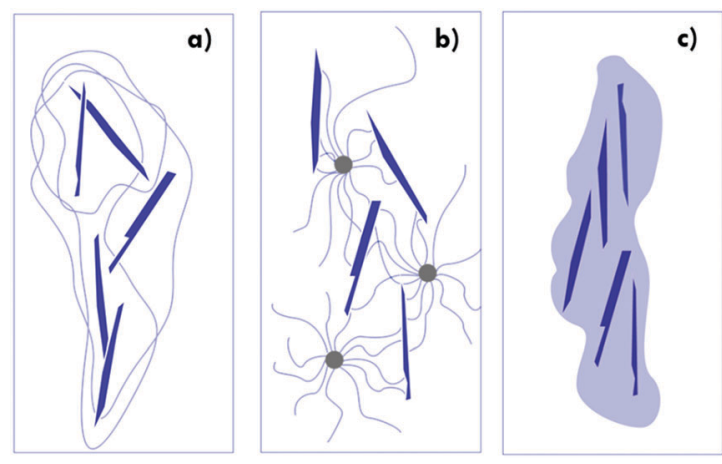

Fig. 9 Schematic representation of (a) the particle-free suspension, (b) composite gel and (c) dry particle-free systems. 
amorphous chains is as efficient as in the retracted amorphous phase. However, the drying process has an additional effect as it shifts the transition to higher temperatures, that may be attributed to a positive pressure effect of the network densification on the nanocrystals. ${ }^{57-60}$ This effect could also explain the higher transition temperature of the composite compared to the particle free system.

\section{Conclusions}

We report a unique and highly efficient way to obtain spincrossover materials by combining metallogel and composite approaches. The final material shows an unusual structure consisting of a semi-crystalline coordination polymer system with an amorphous phase that is reticulated by sulfonated silica particles to obtain a gel. This material exhibits a fully reversible and cooperative SCO behavior with upward and downward transition temperatures of $330 \mathrm{~K}$ and $316 \mathrm{~K}$, respectively. The study of its structural and SCO features sheds light on the important role played by each of the constituents in its transition properties. This emphasizes the sensitivity of the spin transition phenomenon to multiple factors and the necessity to fully characterize and control the system at different scales. Beyond the system investigated here, this nanocomposite approach is very promising for the elaboration of new functional materials fully integrating the specific properties of coordination polymers.

\section{Experimental}

\section{Silica nanoparticles functionalized by sulfonate groups $\left(\mathrm{NP}-\mathrm{SiSO}_{3}\right)$}

Silica nanoparticles were synthesized following the Stöber process. ${ }^{61,62}$ Sulfonate functionalization of the surface proceeded through a modified procedure consisting of two steps. ${ }^{50}$ Stöber particles were first functionalized with thiol groups by silylation with 3-mercaptopropyltrimethoxysilane (MPTMOS 95\%, Aldrich). Typically, $4.12 \mathrm{~g}$ of silica particles were redispersed in a mixture of $410 \mathrm{~mL}$ ethanol and $9 \mathrm{~mL}$ ammonium hydroxide solution before the addition of $4 \mathrm{~mL}$ MPTMOS $\left(5 \mathrm{mmol} \mathrm{g}^{-1}\right.$ silica). The mixture was stirred for $40 \mathrm{~min}$ at room temperature (RT). Subsequently, the reaction mixture was heated to $80{ }^{\circ} \mathrm{C}$ and the total volume was reduced to approximately two-thirds by distillation of ethanol and ammonia at ambient pressure. The mixture was left to cool to RT and was subsequently washed three times with ethanol (by centrifugation at $12000 \mathrm{rpm}$ for $15 \mathrm{~min})$. Finally, oxidation of thiol groups leads to sulfonic acid functionalized particles. In a typical reaction, $3.6 \mathrm{~g}$ of thiolmodified particles were suspended in $150 \mathrm{~mL}$ sulfuric acid $\left(\mathrm{H}_{2} \mathrm{SO}_{4} 30 \%\right.$ (w/w) in $\mathrm{H}_{2} \mathrm{O}$, Sigma Aldrich) and stirred for 2 hours at RT. Washing with ethanol and water by centrifugation was used to recover $\mathrm{SO}_{3}$-modified particles before drying under vacuum. Zeta potential and size distribution measurements were carried out using a Malvern Zetasizer Nano ZS90 instrument giving a strongly negative zeta potential of $c a .-53 \mathrm{mV}$ in $0.5 \mathrm{M}$ acetic acid (pH 2.5) and a hydrodynamic diameter of $c a .200 \mathrm{~nm}$.
The evaluation of the sulfonate density available at the surface of each particle was performed by the titration of thiol grafted prior to their oxidization through the Ellman reaction, taking into account a silica density of $2 \mathrm{~g} \mathrm{~cm}^{-3}$. 49 The sulfonate density could be evaluated to be $3.5 \mathrm{~mol} \mathrm{mg}^{-1}$, i.e. about $10^{5}$ groups per particle.

\section{Particle-free system (Fe/ATrz/SO $\mathrm{SO}_{4}$ suspension)}

$27.8 \mathrm{mg}$ of iron sulfate heptahydrate $\left(\mathrm{FeSO}_{4} \cdot 7 \mathrm{H}_{2} \mathrm{O}, 0.1 \mathrm{mmol}\right)$ (Sigma-Aldrich, 99\%) were dissolved under heating at $50{ }^{\circ} \mathrm{C}$ for 30 minutes in $0.75 \mathrm{~mL}$ of an ethylene glycol : water mixture $(9: 1$ volume ratio) containing $20 \mathrm{mg}$ of ascorbic acid. Parallelly, $50.4 \mathrm{mg}(0.6 \mathrm{mmol})$ of 4 -amino-1,2,4 triazole (ATrz, $\mathrm{C}_{2} \mathrm{H}_{4} \mathrm{~N}_{4}$, Alfa-Aesar, 99\%) was separately dissolved in $0.25 \mathrm{~mL}$ of the same ethylene glycol: water mixture at room temperature. After completion of the dissolution of the iron salt, the ATrz solution was placed in an ice bath and the $\mathrm{FeSO}_{4}$ solution was added dropwise under stirring. This led to a stable suspension that was left to age at $4{ }^{\circ} \mathrm{C}$.

\section{Composite system (NP-SiSO 3 @Fe/ATrz/SO $/ \mathrm{SO}_{4}$ )}

The procedure was analogous to the particle-free systems except that $140 \mathrm{mg}$ of $\mathrm{NP}^{-\mathrm{SiSO}_{3}}$ were suspended in $0.75 \mathrm{~mL}$ of the ethylene glycol: water mixture under sonication for 45 minutes before the iron salt was added. Immediately after the mixing process, a colloid suspension was obtained which turned to a gel after about 20 hours of ageing at $4{ }^{\circ} \mathrm{C}$ as confirmed by the inverse tube test.

\section{Drying of the suspension and composite systems}

Samples were redispersed in $10 \mathrm{~mL}$ of ethanol to induce the formation of a precipitate. The mixture was centrifuged, washed 3 times with $10 \mathrm{~mL}$ of ethanol and the precipitate recovered before drying under ambient air.

\section{UV-spectroscopy}

UV-visible spectra were recorded on freshly prepared mixtures placed in a quartz cuvette with $1 \mathrm{~mm}$ optical path length using a Carry 5000 UV-Vis-NIR spectrophotometer. The heating and cooling ramps and the acquisition parameters were chosen to ensure a mean scan speed of $5 \mathrm{~K} \mathrm{~min}^{-1}$.

\section{Differential scanning calorimetry}

DSC measurements were performed on a TA instrument model Q20. Aluminum capsules were loaded with $20-50 \mathrm{mg}$ of the sample and sealed. The set-up and enthalpies were calibrated for temperature using an indium reference $\left(430 \mathrm{~K}, 3.3 \mathrm{~J} \mathrm{~mol}^{-1}\right.$ ). Cooling and heating sweeps were performed at a scanning rate of $5 \mathrm{~K} \mathrm{~min}^{-1}$ in a $\mathrm{N}_{2}(\mathrm{~g})$ atmosphere. The transition temperatures were derived by considering the maximum $\left(T_{\max }\right)$ of the thermal anomalies.

\section{X-ray powder diffraction}

XRPD measurements were carried out using $\mathrm{Cu} \mathrm{K} \alpha 1$ radiation either on a Philips PW 1830 diffractometer at room temperature or on a Panalytical Xpert pro MPD diffractometer for temperaturedependent experiments. In the latter case, the samples were 
deposited on a Si monocrystal in order to have a flat background and then placed in an Anton Paar HTK 1200N oven. The heating and cooling ramps and the acquisition parameters were chosen to ensure a mean scan speed of approximately $1 \mathrm{~K} \mathrm{~min}^{-1}$.

\section{Rheological measurements}

Rheological measurements were conducted on an MCR 302 Anton-Paar rheometer. The geometry used was a $25 \mathrm{~mm}$ diameter disk with a rough surface (reference PP 25/S). Freshly prepared samples were placed in PTFE circular chambers with an inner diameter slightly larger than the geometry allowing rheological measurements in the low modulus range. The rheological behavior of the samples was investigated under sinusoidal deformations with a frequency of oscillations ranging from 0.1 to $100 \mathrm{~Hz}$ at the set strain (0.1\%) and under a normal force of $0.04 \mathrm{~N}$. All experiments and their corresponding measurements were conducted in triplicate.

\section{Magnetic measurements}

Magnetic measurements were carried out using a MPMS-5 Quantum Design SQuID (Superconducting Quantum Interference Device) magnetometer operating with an external magnetic field of $0.5 \mathrm{~T}$ within the $260-355 \mathrm{~K}$ temperature range. Freshly prepared samples (about $200 \mathrm{mg}$ of the Fe-ATrz suspension or $170 \mathrm{mg}$ of the $\mathrm{NP}_{-} \mathrm{SiSO}_{3}$ @Fe-ATrz composite) were introduced into an EPR tube. The tube was then sealed, and after 9 days the tube was fixed to a cane and placed in the magnetometer at $298 \mathrm{~K}$. Cooling and heating sweeps were performed at a scanning rate of $5 \mathrm{~K} \mathrm{~min}^{-1}$. Paramagnetic susceptibility data $\left(\chi_{\text {para }}\right)$ were obtained subtracting from the experimental susceptibility data, the diamagnetic contributions (sample, RPE tube). These latter contributions were estimated from the slope of the $\chi T$ curve at high temperature (344-356 K) over which no spin state change takes place. The magnetic susceptibity $v s$. temperature curves were then normalized to allow the comparison of the thermic loop between all samples.

\section{Electron microscopy}

Scanning electron microscopy (SEM) imaging was performed using a Variable Pressure Hitachi S-3400N after depositing a thin layer of the sample on aluminum pads without any further metallization.

All the Transmission Electron Microscopy (TEM) observations were conducted on a FEI Technai Spirit G2 operating at $120 \mathrm{kV}$ equipped with a Gatan cryo-holder operating at $-180{ }^{\circ} \mathrm{C}$. Images were recorded on a Gatan Orius CCD camera.

For cryo-TEM, a drop of sample was deposited on plasma treated QUANTIFOIL grids before vitrification: the excess sample was removed by blotting with filter paper (Whatman \#4) to obtain a thin film before plunging the grid into liquid ethane cooled by liquid nitrogen.

For freeze-fracture experiments, samples placed between two copper holders were rapidly frozen by plunging them into liquid nitrogen. They were kept frozen and transferred into a freeze-fracture apparatus developed by Dr J.-C. Homo (IGBMC, Strasbourg). The samples were cryo-cleaved and platinum was evaporated onto the sample at a $45^{\circ}$ angle, and then carbon at a $90^{\circ}$ angle with respect to the surface. The samples were warmed up to room temperature and the replicas were rinsed by acidic treatment and deposited on 400 mesh grids.

\section{Conflicts of interest}

There are no conflicts to declare.

\section{Acknowledgements}

The authors would like to thank L. Frenck, J. Camperi and E. Coquin for the screening of polar solvents to obtain metallogels, B. Baptiste and L. Delbes for the temperature-dependent XRPD measurements performed on the IMPMC XRD platform and E. Rivière for the magnetic measurements performed on the ICMMO Technical Platform.

\section{References}

1 Spin-Crossover Materials, ed. M. A. Halcrow, John Wiley \& Sons, Ltd, 2013.

2 P. Gütlich, Y. Garcia and H. A. Goodwin, Chem. Soc. Rev., 2000, 29, 419.

3 P. J. van Koningsbruggen, Y. Garcia, E. Codjovi, R. Lapouyade, O. Kahn, L. Fournès and L. Rabardel, J. Mater. Chem., 1997, 7, 2069.

4 O. Kahn and C. Jay Martinez, Science, 1998, 279, 44.

5 A. Grosjean, N. Daro, B. Kauffmann, A. Kaiba, J. F. Létard and P. Guionneau, Chem. Commun., 2011, 47, 12382.

6 X. X. Wu, Y. Y. Wang, P. Yang, Y. Y. Xu, J. Zhong Huo, B. Ding, Y. Wang and X. G. Wang, Cryst. Growth Des., 2014, 14, 477.

7 A. Michalowicz, J. Moscovici, B. Ducourant, D. Cracco and O. Kahn, Chem. Mater., 1995, 7, 1833.

8 J. Kröber, J. P. Audière, R. Claude, E. Codjovi, O. Kahn, J. G. Haasnoot, F. Grolière, C. Jay, A. Bousseksou, J. Linarès, F. Varret and A. Gontier-Vassal, Chem. Mater., 1994, 6, 1404.

9 O. Roubeau, J. M. Alcazar Gomez, E. Balskus, J. J. A. Kolnaar, J. G. Haasnoot and J. Reedijk, New J. Chem., 2001, 25, 144.

10 S. Kume, K. Kuroiwa and N. Kimizuka, Chem. Commun., 2006, 2442.

11 L. G. Lavrenova and O. G. Shakirova, Eur. J. Inorg. Chem., 2013, 670 .

12 M. Rubio and D. López, Eur. Polym. J., 2009, 45, 3339.

13 O. Roubeau, Chem. - Eur. J., 2012, 18, 15230.

14 M. Verelst, L. Sommier, P. Lecante, A. Mosset and O. Kahn, Chem. Mater., 1998, 10, 980.

15 Y. A. Tobon, L. Kabalan, S. Bonhommeau, N. Daro, A. Grosjean, P. Guionneau, S. Matar, J. F. Létard and F. Guillaume, Phys. Chem. Chem. Phys., 2013, 15, 18128.

16 A. Tokarev, L. Salmon, Y. Guari, W. Nicolazzi, G. Molnár and A. Bousseksou, Chem. Commun., 2010, 46, 8011.

17 E. M. Levin, Q. Chen and S. L. Bud'ko, J. Polym. Sci., Part B: Polym. Phys., 2012, 50, 129. 
18 A. Tokarev, J. Long, Y. Guari, J. Larionova, F. Quignard, P. Agulhon, M. Robitzer, G. Molnár, L. Salmon and A. Bousseksou, New J. Chem., 2013, 37, 3420.

19 S. Cobo, G. Molnár, J. A. Real and A. Bousseksou, Angew. Chem., Int. Ed., 2006, 45, 5786.

20 M. S. Alam, M. Stocker, K. Gieb, P. Müller, M. Haryono, K. Student and A. Grohmann, Angew. Chem., Int. Ed., 2010, 49, 1159.

21 C. Faulmann, J. Chahine, I. Malfant, D. de Caro, B. Cormary and L. A. Valade, Dalton Trans., 2011, 40, 2480.

22 T. Q. Hung, F. Terki, S. Kamara, M. Dehbaoui, S. Charar, B. Sinha, C. Kim, P. Gandit, I. A. Gural'skiy, G. Molnar, L. Salmon, H. J. Shepherd and A. Bousseksou, Angew. Chem., Int. Ed., 2013, 52, 1185.

23 P. Terech and R. G. Weiss, Chem. Rev., 1997, 97, 3133.

24 A. Y. Tam and V. W. Yam, Chem. Soc. Rev., 2013, 42, 1540.

25 J. Zhang and C.-Y. Su, Coord. Chem. Rev., 2013, 257, 1373.

26 C. Janiak, Dalton Trans., 2003, 2781.

27 J. A. Foster, M.-O. M. Piepenbrock, G. O. Lloyd, N. Clarke, J. A. K. Howard and J. W. Steed, Nat. Chem., 2010, 2, 1037.

28 S. Saha, E.-M. Schön, C. Cativiela, D. Díaz Díaz and R. Banerjee, Chem. - Eur. J., 2013, 19, 9562.

29 Q. Lin, T.-T. Lu, X. Zhu, B. Sun, Q.-P. Yang, T.-B. Wei and Y.-M. Zhang, Chem. Commun., 2015, 51, 1635.

30 M. Martínez-Calvo, O. Kotova, M. E. Möbius, A. P. Bell, T. McCabe, J. J. Boland and T. Gunnlaugsson, J. Am. Chem. Soc., 2015, 137, 1983.

31 O. Roubeau, A. Colin, V. Schmitt and R. Clérac, Angew. Chem., Int. Ed., 2004, 43, 3283.

32 K. Kuroiwa, T. Shibata, A. Takada, N. Nemoto and N. Kimizuka, J. Am. Chem. Soc., 2004, 126, 2016.

33 M. Seredyuk, A. B. Gaspar, V. Ksenofontov, S. Reiman, Y. Galyametdinov, W. Haase, E. Rentschler and P. Gütlich, Chem. Mater., 2006, 18, 2513.

34 P. Grondin, O. Roubeau, M. Castro, H. Saadaoui, A. Colin and R. Clérac, Langmuir, 2010, 26, 5184.

35 T. Fujigaya, D.-L. Jiang and T. Aida, Chem. - Asian J., 2007, 2, 106.

36 J. Dugay, M. Giménez-Marqués, T. Kozlova, H. W. Zandbergen, E. Coronado and H. S. J. van der Zant, Adv. Mater., 2015, 27, 1288.

37 X. J. Liu, Y. Moritomo, A. Nakamura, T. Hirao, S. Toyazaki and N. Kojima, J. Phys. Soc. Jpn., 2001, 70, 2521.

38 A. Nakamoto, Y. Ono, N. Kojima, D. Matsumura and T. Yokoyama, Chem. Lett., 2003, 32, 336.

39 Y. Chen, J.-G. Ma, J.-J. Zhang, W. Shi, P. Cheng, D.-Z. Liao and S.-P. Yan, Chem. Commun., 2010, 46, 5073.

40 Y. Raza, F. Volatron, S. Moldovan, O. Ersen, V. Huc, C. Martini, F. Brisset, A. Gloter, O. Stéphan, A. Bousseksou, L. Catala and T. Mallah, Chem. Commun., 2011, 47, 11501.

41 A. Tissot, J.-F. Bardeau, E. Rivière, F. Brisset and M.-L. A. Boillot, Dalton Trans., 2010, 39, 7806.
42 P. Durand, S. Pillet, E.-E. Bendeif, C. Carteret, M. Bouazaoui, H. El Hamzaoui, B. Capoen, L. Salmon, S. Hébert, J. Ghanbaja, L. Aranda and D. Schaniel, J. Mater. Chem. C, 2013, 1, 1933.

43 A. Holovchenko, J. Dugay, M. Giménez-Marqués, R. TorresCavanillas, E. Coronado and H. S. J. van der Zant, Adv. Mater., 2016, 28, 7228.

44 D. Qiu, L. Gu, X.-L. Sun, D.-H. Ren, Z.-G. Gu and Z. Li, RSC Adv., 2014, 4, 61313.

45 A. Sanchez-Ferrer, I. Braunlich, J. Ruokolainen, M. Bauer, R. Schepper, P. Smith, W. Caseri and R. Mezzenga, RSC Adv., 2014, 4, 60842.

46 I. Bräunlich, A. Sánchez-Ferrer, M. Bauer, R. Schepper, P. Knüsel, J. Dshemuchadse, R. Mezzenga and W. Caseri, Inorg. Chem., 2014, 53, 3546.

47 P. Gütlich, A. Hauser and H. Spiering, Angew. Chem., Int. Ed. Engl., 1994, 33, 2024.

48 L. G. Lavrenova, O. G. Shakirova, V. N. Ikorskii, V. A. Varnek, L. A. Sheludyakova and S. V. Larionov, Russ. J. Coord. Chem., 2003, 29, 22.

49 J. Wu, J. Silvent, T. Coradin and C. Aimé, Langmuir, 2012, 28, 2156.

50 C. Aimé, G. Mosser, G. Pembouong, L. Bouteiller and T. Coradin, Nanoscale, 2012, 4, 7121.

51 R. C. Kramb and C. F. Zukoski, J. Rheol., 2011, 55, 1069.

52 M. M. Dîrtu, A. Rotaru, D. Gillard, J. Linares, E. Codjovi, B. Tinant and Y. Garcia, Inorg. Chem., 2009, 48, 7838.

53 M. M. Dîrtu, A. D. Naik, A. Rotaru, L. Spinu, D. Poelman and Y. Garcia, Inorg. Chem., 2016, 55, 4278.

54 M. Schmutz and P. J. Mésini, in Handbook of CryoPreparation Methods for Electron Microscopy, ed. A. Cavelier, D. Spehner and B. M. Humbel, CRC Press, Boca Raton, FL, 2008, pp. 411-430.

55 A. Tissot, C. Enachescu and M. L. Boillot, J. Mater. Chem., 2012, 22, 20451.

56 A. Tokarev, L. Salmon, Y. Guari, G. Molnár and A. Bousseksou, New J. Chem., 2011, 35, 2081.

57 C. Roux, J. Zarembowitch, J. P. Itié, A. Polian and M. Verdaguer, Inorg. Chem., 1996, 35, 574.

58 M. Rubio, R. Hernández, A. Nogales, A. Roig and D. López, Eur. Polym. J., 2011, 47, 52.

59 P. Gütlich, A. B. Gaspar and Y. Garcia, Beilstein J. Org. Chem., 2013, 9, 342 .

60 T. Zhao, L. Cuignet, M. M. Dîrtu, M. Wolff, V. Sapsojevic, I. Boldog, A. Rotaru, Y. Garcia and C. Janiak, J. Mater. Chem. $C, 2015,3,7802$.

61 W. Stöber, A. Fink and E. J. Bohn, J. Colloid Interface Sci., 1968, 26, 62.

62 L. C. J. Thomassen, A. Aerts, V. Rabolli, D. Lison, L. Gonzalez, M. Kirsh-Volders, D. Napierska, P. H. Hoet, C. E. A. Kirschhock and J. A. Martens, Langmuir, 2010, 26, 328. 